\title{
O USO DA HIDRATAÇÃO COMO PARÂMETRO PARA ESTIMAR O DESEMPENHO DE SEMENTES DE SOJA
}

\author{
OSMAR PAULO BECKERT
}

Tese apresentada à Escola Superior de Agricultura "Luiz de Queiroz", Universidade de São Paulo, para obtenção do título de Doutor em Agronomia, Área de Concentração: Fitotecnia

\footnotetext{
PIRACICABA

Estado de São Paulo - Brasil

Junho - 2001
} 


\title{
O USO DA HIDRATAÇÃO COMO PARÂMETRO PARA ESTIMAR O DESEMPENHO DE SEMENTES DE SOJA
}

\author{
OSMAR PAULO BECKERT \\ Engenheiro Agrônomo
}

Orientador: Prof. Dr. WALTER RODRIGUES DA SILVA

Tese apresentada à Escola Superior de Agricultura "Luiz de Queiroz", Universidade de São Paulo, para obtenção do título de Doutor em Agronomia, Área de Concentração: Fitotecnia

\section{PIRACICABA}

Estado de São Paulo - Brasil

Junho - 2001 
Dados I nternacionais de Catalogação na Publicação (CI P) DI VISÃO DE BI BLI OTECA E DOCUMENTAÇÃ̃O - Campus “Luiz de Queiroz”/ USP

\author{
Beckert, Osmar Paulo \\ O uso da hidratação como parâmetro para estimar o desempenho de sementes de \\ soja / Osmar Paulo Beckert. - - Piracicaba, 2001. \\ $37 \mathrm{p}$. \\ Tese (doutorado) - Escola Superior de Agricultura Luiz de Queiroz, 2001. \\ Bibliografia. \\ 1. Hidratação 2. Qualidade fisiológica 3. Semente de soja 4. Embebição I. Título
}

CDD 633.34

"Permitida a cópia total ou parcial deste documento, desde que citada a fonte - $\mathrm{O}$ autor" 


\title{
O USO DA HIDRATAÇÃO COMO PARÂMETRO PARA ESTIMAR O DESEMPENHO DE SEMENTES DE SOJA
}

\author{
OSMAR PAULO BECKERT
}

Aprovada em: 27.08.2001

Comissão julgadora:

Prof. Dr. Walter Rodrigues da Silva

ESALQ/USP

Prof ${ }^{\mathrm{a}}$.Dr ${ }^{\mathrm{a}}$. Ana Dionisia da Luz Coelho Novembre

ESALQ/USP

Prof. Dr. Cláudio Cavariani

FCA/UNESP

Prof. Dr. Francisco Amaral Villela

FAEM/UFPEL

Prof. Dr. Nelson Moreira de Carvalho

FCAVJ/UNESP

Prof. WALTER RODRIGUES DA SILVA

Orientador 
A meus pais, Paulo e Lucia

a meus sogros, Hermes e Ingrid

\section{OFEREÇO}

À querida Evelin, esposa e companheira, e filhos Tiago e Ricardo,

pelo carinho, compreensão e paciência, 


\section{AGRADECIMENTOS}

Ao Prof. Dr. Walter Rodrigues da Silva, pela orientação segura e objetiva e pela amizade.

À Embrapa/Serviço de Produção de Sementes Básicas, pela oportunidade de realização do curso e à Gerência Local de Ponta Grossa, pelo fornecimento das sementes..

À Universidade Estadual de Ponta Grossa/UEPG, pela liberação para realização do curso.

Aos Professores, especialmente Júlio Marcos Filho, Silvio Moure Cícero, José Otávio Machado Menten, Antonio Luis Fancelli, Durval Dourado Neto, João Alexio Scarpare Filho e Paulo Kageyama, pelos ensinamentos ministrados.

Ao Conselho Nacional de Desenvolvimento Científico e Tecnológico/CNPq, pela bolsa de estudo concedida.

Aos colegas de curso, Angélica B. Rodo, Marcelo H. Miguel, Roseli F. Caseiro, Rudimar Molin e Salvador B. Torres pela amizade, colaboração e momentos compartilhados.

Às Engenheiras Agrônomas Ana Dionisia L. C. Novembre, Helena M.C. Pescarin Chamma e Maria Heloisa D. Moraes, pela colaboração.

Ao professor Carlos Tadeu S. Dias, pela colaboração nas análises estatísticas. 
Aos funcionários do Departamento de Produção Vegetal, especialmente Maria Ivete Monteiro de Almeida, Ilze Helena C. G. das Neves, Hodair Luiz Banzatto Junior, João Batista Bigeli e João E. Jabur Filho, pelo auxílio durante o curso.

Às famílias Villela (Francisco, Lúcia, Arthur e Bethânia), Chaves (Alexander, Flor de Maria e Silvia) e Molin (Rudimar, Ana, Daiane e Felipe) pelos momentos agradáveis compartilhados.

À todos que, de alguma forma, contribuíram para a realização do curso. 


\section{SUMÁRIO}

\begin{tabular}{|c|c|}
\hline & Página \\
\hline LISTA DE FIGURAS ......... & vii \\
\hline LISTA DE TABELAS .......... & viii \\
\hline RESUMO ..... & $\mathrm{xi}$ \\
\hline SUMMARY ............. & xiii \\
\hline 1 INTRODUÇÃO ........................... & 1 \\
\hline 2 REVISÃO DE LITERATURA ....... & 2 \\
\hline 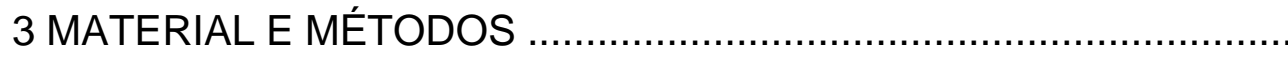 & 7 \\
\hline 3.1 Determinação do grau de umidade & 7 \\
\hline 3.2 Teste de germinação ......................... & 7 \\
\hline 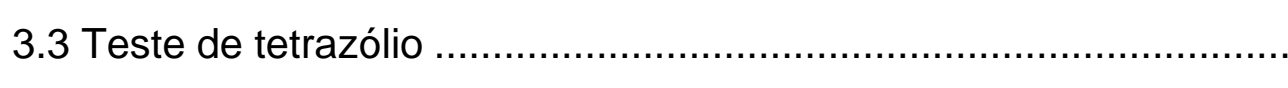 & 8 \\
\hline 3.4 Teste de envelhecimento acelerado .. & 8 \\
\hline 3.5 Testes de comprimento da raiz e da plântula . & 8 \\
\hline 3.6 Peso de matéria seca da plântula ....... & 8 \\
\hline 3.7 Teste de condutividade elétrica ... & 9 \\
\hline 3.8 Teste de emergência de plântulas . & 9 \\
\hline 4 RESULTADOS E DISCUSSÃO ........... & 12 \\
\hline 5 CONCLUSÕES & 30 \\
\hline REFERÊNCIAS BIBLIOGRÁFIC/ & 31 \\
\hline
\end{tabular}




\section{LISTA DE FIGURAS}

Página

1 Dados de teor de água (\%) obtidos em sementes de soja (lote A) classificadas por espessura após a aplicação de períodos (3, 6, 9

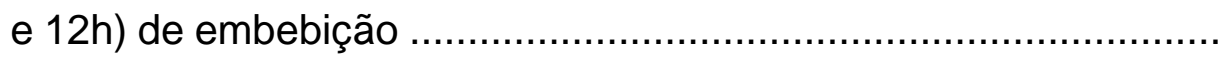

2 Dados de teor de água (\%) obtidos em sementes de soja (lote B) classificadas por espessura após a aplicação de períodos (3, 6, 9 e 12h) de embebição

3 Dados de teor de água (\%) obtidos em sementes de soja (lote $\mathrm{C}$ ) classificadas por espessura após a aplicação de períodos (3, 6, 9 e 12h) de embebição .................................................................... 


\section{LISTA DE TABELAS}

Página

1 Esquema de análise de variância adotado para os dados (lotes A, B e C) dos testes de caracterização qualitativa inicial e para os da freqüência de indivíduos presentes em cada espessura após a embebição

2 Esquema de análise de variância empregado por lote para os dados dos testes de avaliação da Qualidade fisiológica realizados após a embebição .....................................................

3 Esquema de análise de variância empregado na análise conjunta dos lotes (A, B e C) para os dados dos testes de avaliação da qualidade fisiológica realizados após a embebição

4 Dados da qualidade fisiológica inicial dos lotes A, B e C avaliada pelos testes de germinação $(G)$, de envelhecimento artificial (EA), de tetrazólio/vigor (TZ), de comprimentos da raiz (CR) e da plântula (CP), de peso de matéria seca da plântula (MS), de condutividade elétrica $(C)$ e de emergência de plântula $(E)$ 
5 Dados de germinação (\%) obtidos em sementes de soja (lotes A, B e C) classificadas por espessura após a aplicação dos períodos (3, 6, 9 e 12h) de embebição

6 Dados de tetrazólio/vigor (\%) obtidos em sementes de soja (lotes A, B e C) classificadas por espessura após a aplicação dos períodos $(3,6,9$ e 12h) de embebição ...........................................

7 Dados de comprimento $(\mathrm{cm})$ da raiz obtidos em sementes de soja (lotes A, B e C) classificadas por espessura após a aplicação dos períodos (3, 6, 9 e 12h) de embebição .........................................

8 Dados de comprimento $(\mathrm{cm})$ da plântula obtidos em sementes de soja (lotes A, B e C) classificadas por espessura após a aplicação dos períodos (3, 6, 9 e 12h) de embebição

9 Dados do peso $(\mathrm{mg})$ de matéria seca da plântula obtidos em sementes de soja (lotes A, B e C) classificadas por espessura após a aplicação dos períodos (3, 6, 9 e 12h) de embebição .........

10 Análise conjunta (lotes $A, B$ e $C$ ): dados do teor de água (TA), germinação $(\mathrm{G})$, tetrazólio/vigor (TZ), comprimentos da raiz $(\mathrm{CR})$ e da plântula (CP) e peso de matéria seca da plântula (MS) obtidos em sementes de soja classificadas por espessura após a aplicação dos períodos (3, 6, 9 e 12h) de embebição ................... 
11 Ocorrências de superioridades, entre as sementes com diferentes espessuras, verificadas nos testes de avaliação da qualidade fisiológica realizados após os períodos de embebição: número e freqüência (\%), obtidos num total de 20 possibilidades (5 testes em 4 períodos de embebição), considerando a análise conjunta dos lotes (Tabela 10) segundo interpretações baseadas em critério estatístico e em valores absolutos

12 Dados de freqüência (\%) da presença, por espessura, de sementes de soja (lotes A, B e C) classificadas após a aplicação dos períodos (3, 6, 9 e 12h) de embebição ...................................

13 Coeficientes de correlação entre as freqüências (\%) de presença de sementes, por espessura (Tabela 12), e os testes de germinação (G), de envelhecimento artificial (EA), de tetrazólio/vigor (TZ), de comprimentos da raiz (CR) e da plântula $(\mathrm{CP})$, de peso de matéria seca da plântula (MS), de condutividade elétrica $(C)$ e de emergência de plântulas (E) aplicados para a estimativa da qualidade fisiológica inicial dos lotes (Tabela 4) 


\title{
O USO DA HIDRATAÇÃO COMO PARÂMETRO PARA ESTIMAR O DESEMPENHO DE SEMENTES DE SOJA
}

\author{
Autor: OSMAR PAULO BECKERT \\ Orientador: Prof. Dr. WALTER RODRIGUES DA SILVA
}

\section{RESUMO}

O objetivo do presente trabalho foi o de estudar as relações entre as variações na hidratação inicial, no tamanho e na qualidade fisiológica das sementes de soja. Para tanto, 3 lotes (cultivar BRS-157), com qualidade fisiológica distinta, tiveram as sementes padronizadas por espessura (13/64 de polegada) e submetidas a embebições a $20^{\circ} \mathrm{C}$ em períodos variáveis $(3,6,9$ e 12h). Após as embebições, as sementes foram reclassificadas por espessura e, posteriormente à estimativa da freqüência de indivíduos presentes em cada fração, submetidas às avaliações da qualidade fisiológica. Foi verificado que a qualidade fisiológica afeta o teor de água e a espessura alcançados pelas sementes de soja durante a embebição; assim, há a possibilidade de comparar o desempenho fisiológico relativo de lotes por intermédio dos dados de freqüência de espessura em sementes hidratadas. 


\title{
THE USE OF THE HYDRATION AS A PARAMETER TO ESTIMATE THE QUALITY OF SOYBEAN SEEDS
}

\author{
Author: OSMAR PAULO BECKERT \\ Adviser: Prof. Dr. WALTER RODRIGUES DA SILVA
}

\section{SUMMARY}

The objective of the present work was to study the relationships among the variations in the initial hydration, size and on physiologic quality of soybean seeds. Three lots (cv.BRS-157) with different physiologic quality had the seeds standardized according to thickness (13/64 inches) and submitted to hydration at $20^{\circ} \mathrm{C}$ in variable periods $(3,6,9$ and $12 \mathrm{~h})$. After the hydration, the seeds were classified according to thickness and subsequently the individuals' frequency in each fraction was estimated, submitted to evaluations of the physiologic quality. The physiologic quality was verified to affect the water content and the thickness reached by the soybean seeds during the hydration; therefore, it is possible to compare the relative physiologic quality of lots through the thickness frequency data in moisturized seeds. 


\section{INTRODUÇÃO}

Para que uma semente germine, é necessário que o meio forneça água suficiente para a ativação das reações químicas relacionadas ao metabolismo e, com isto, seja desencadeado o processo de retomada do desenvolvimento do embrião. Assim, a água, durante o processo de germinação, acha-se diretamente envolvida na digestão, na mobilização e na utilização de nutrientes pelas células embrionárias.

A hidratação inicia-se na embebição e tem velocidade dependente, principalmente, da composição química da semente, da permeabilidade do tegumento e da presença de água nas formas líquida ou gasosa no meio em que o processo está ocorrendo. Contudo, estudos têm sugerido que, em função da condição fisiológica das sementes, a hidratação pode ter a velocidade afetada e, portanto, atuar como fenômeno indicativo da qualidade fisiológica da semente (Rocha et al., 1984; Souza et al., 1996). Levando em conta que uma das decorrências físicas, advindas da hidratação, é a alteração no tamanho das sementes (Kim et al.,1994), pode-se pressupor a existência de relações entre as suas dimensões, durante a embebição, e a qualidade fisiológica.

Assim, o objetivo do presente trabalho foi o de estudar as relações entre as variações na hidratação inicial, no tamanho e na qualidade fisiológica das sementes de soja. 


\section{REVISÃO DE LITERATURA}

A absorção de água é requisito para o desencadeamento da retomada do crescimento do embrião nas sementes ortodoxas, em estado de latência, como conseqüência da ativação de enzimas, da digestão de reservas e da assimilação de nutrientes (Copeland \& McDonald, 1995).

Sob condições não restritivas de suprimento, a absorção de água obedece a um padrão trifásico. $\mathrm{Na}$ fase I, denominada embebição, a absorção ocorre de modo rápido em sementes vivas ou mortas. Em seguida a esta fase, há redução acentuada na velocidade de hidratação acompanhada por eventos preparatórios para a emergência radicular. Embora as sementes mortas ou dormentes possam atingir a fase II, somente as potencialmente capazes de germinar alcançam a fase III, caracterizada por elevadas taxa de absorção e atividade respiratória, com início identificado pela protrusão do eixo embrionário (Labouriau, 1983; Marcos Filho, 1986; Carvalho \& Nakagawa, 1988; Bewley \& Black, 1994; Bradford, 1995; Copeland \& McDonald, 1995). A duração de cada fase depende de propriedades inerentes às sementes e às condições ambientais presentes (Bewley \& Black, 1994). Rosseto et al. (1997) observaram, em lotes de sementes de soja com qualidade fisiológica variável, a ocorrência de absorção de água em modelo similar ao do padrão trifásico e, adicionalmente, delimitaram o final da fase I após, aproximadamente, um período de $12 \mathrm{~h}$ com as sementes apresentando teores de água entre 40 e 45\%; também Motta \& Silva (1997), trabalhando com sementes de trigo, verificaram que a marcha da absorção de água apresentou padrão trifásico característico, com uma fase inicial $(21 \mathrm{~h})$ de rápida absorção, seguida de fase intermediária de 
absorção lenta (21 a 36 h) e, posteriormente, uma nova fase de elevada velocidade de absorção.

A absorção inicial (embebição) sofre interferências da composição química das sementes, da permeabilidade do tegumento, da disponibilidade de água nos estados líquido ou gasoso (Ching, 1972; Mayer \& Mayber, 1978; Carvalho \& Nakagawa, 1988; Vertucci, 1989; McCormac \& Keefe, 1990; Obroucheva et al., 1993; Bewley \& Black, 1994; Copeland \& McDonald, 1995), da temperatura (Waggoner \& Parlange, 1976; Murphy \& Noland, 1982; Popinigis, 1985), da área de contato entre a semente e o substrato Ching, 1972; Calero et al., 1981; Shieh \& McDonald, 1982; LeDeunf, 1989) e do teor inicial de água das sementes (Hobbs \& Obendorf, 1972; Vertucci \& Leopold, 1983). Nesta fase, a entrada de água promove o aumento do volume da semente e conseqüente ruptura do envoltório que, por sua vez, permitirá o desenvolvimento da plântula (Mayer \& Mayber, 1978; Copeland \& McDonald, 1995). A entrada e a distribuição da água nas sementes, reguladas pelo potencial de água celular, ocorrem tanto por capilaridade como por difusão, no sentido do maior para o menor potencial hídrico. Desta forma, a embebição tem sido entendida como um processo físico relacionado, principalmente, com as características de permeabilidade do envoltório e com as propriedades dos colóides constituintes das sementes (Carvalho \& Nakagawa, 1988; Woodstock, 1988; Bewley \& Black, 1994). Segundo Kim et al. (1994), a hidratação das sementes de soja relaciona-se, linearmente, com a expansão do volume.

Os principais componentes químicos da semente, responsáveis pela embebição, são a proteína (Mayer \& Mayber, 1978; Woodstock, 1988; Copeland \& McDonald, 1995) e, em menor intensidade, a celulose e as substâncias pécticas (Mayer \& Mayber, 1978; Copeland \& McDonald, 1995); o amido e, principalmente, os lipídios apresentam reduzida interferência no processo (Mayer \& Mayber, 1978; Copeland \& McDonald, 1995). McDonald et al. (1988b) observaram que os eixos embrionários de sementes de soja hidratam-se mais rapidamente, do que as outras estruturas, em virtude do seu 
maior conteúdo de proteína. Armstrong \& McDonald (1992) verificaram que a absorção inicial de água, pelo eixo embrionário de sementes de soja, foi mais rápida do que a presente nos cotilédones e no tegumento. Da mesma forma, Vertucci \& Leopold (1987), estudando várias espécies de leguminosas, detectaram que os eixos embrionários possuem mais sítios de ligação com a água do que os cotilédones, em função de seu maior conteúdo de proteína. Clarke \& DePauw (1989), estudando cruzamentos entre cultivares de trigo, verificaram que a taxa de embebição das sementes estava correlacionada positivamente com o conteúdo de proteína e negativamente com o peso das sementes. Blacklow (1972) observou, em milho, que o pericarpo, o endosperma e o embrião, absorvendo água em velocidades distintas, alcançaram a saturação em períodos variáveis de tempo. McDonald et al. (1994), avaliando a marcha de absorção de água em sementes de milho, verificaram que o embrião absorveu mais água do que o endosperma.

De um modo geral, tem sido observado que as sementes com maiores teores de proteína, ou maiores valores para a relação embrião/endosperma, são as que apresentam superioridade na capacidade de absorção (Ching, 1972; Marcos Filho, 1986; McDonald et al., 1988b). Para Copeland e McDonald (1995), a diferença entre as embebições de sementes protéicas e amiláceas pode ser observada considerando a soja e o milho; enquanto as sementes de soja absorvem de duas a cinco vezes seu peso de matéria seca em água, as de milho absorvem de 1,5 a duas vezes.

A permeabilidade do tegumento é, normalmente, maior nas regiões em que apresenta-se mais delgado como, por exemplo, a representada pelo hilo (Bewley \& Black, 1994; Copeland \& McDonald, 1995). Quando a embebição é impedida em virtude da impermeabilidade do tegumento, como é o caso presente nas sementes duras, a germinação não ocorre (Bradford, 1995). McDonald et al. (1988a) concluíram que, durante as primeiras 8 horas de embebição, o tegumento das sementes de soja atua regulando a passagem da água para, após este período, tornar-se totalmente permeável podendo, 
inclusive, servir como reservatório de água para uso do eixo embrionário. Arantes et al. (1994), em pesquisa envolvendo vários cultivares de soja, não constataram relações consistentes entre a espessura do tegumento, a embebição e a qualidade fisiológica das sementes; apesar disso, observaram que no cultivar IAC-8, portador das sementes de tegumento mais espesso, a embebição foi favorecida e a emergência das plântulas prejudicada.

A integridade do envoltório interfere na absorção de água pelas sementes. Powell \& Matthews (1979) observaram que a danificação do tegumento, de sementes de ervilha, favoreceu o aumento da velocidade de embebição sem interferir na lixiviação de solutos medida em teste de condutividade elétrica. McCormac \& Keefe (1990), trabalhando com sementes de couve-flor, constataram que o dano mecânico no tegumento resultou em incremento na embebição e decréscimo no comprimento da raiz. Sementes de trigo, debulhadas mecanicamente, apresentaram taxa de embebição superior à das debulhadas manualmente, possivelmente em função da maior taxa de danificações mecânicas no pericarpo (Clarke \& DePauw, 1989).

Algumas pesquisas têm sido conduzidas buscando associar a qualidade fisiológica com a velocidade de absorção de água pelas sementes; os resultados alcançados, contudo, não são conclusivos. Rocha et al. (1984), em avaliação da capacidade de absorção de água pelas sementes de soja, ao verificarem que as de colheita retardada tiveram elevação na velocidade de embebição em relação às obtidas em colheitas não retardadas, concluíram que as sementes de maior qualidade embebem mais lentamente. Souza et al. (1996), estudando as características físicas e fisiológicas associadas à absorção de água em sementes de Calopogonium mucunoides, encontraram correlação positiva entre a velocidade de intumescimento, ou de aumento de volume, e o somatório das freqüências de sementes mortas e de plântulas anormais. Também Shepard \& Naylor (1996), trabalhando com sementes de sorgo colhidas precocemente e no ponto de maturidade fisiológica, observaram que as sementes imaturas, além de menores peso, tamanho e densidade, 
possuíam pericarpo que possibilitou embebição mais acentuada e com maior lixiviação de eletrólitos. De acordo com Hegarty (1978), a hidratação ocorre em taxas diferentes para cada indivíduo de um lote de sementes, sendo que as sementes mortas podem se hidratar mais rapidamente do que as capazes de germinar. Leopold (1980), similarmente, verificou que as sementes mortas, além de embeberem mais rapidamente do que as vivas, apresentaram maior lixiviação de solutos; da mesma forma, Murphy \& Noland (1982), em sementes de beterraba mortas pelo calor, encontraram acentuado incremento, na embebição e na lixiviação de solutos, em relação ao verificado nas sementes vivas. Por outro lado, segundo McDonald et al. (1988b), a hidratação de sementes de soja ocorreu de forma similar, em água líquida, independentemente do estádio de deterioração. Também Woodstock \& Tao (1981) não observaram diferenças na absorção de água em eixos embrionários de soja de diferentes qualidades fisiológicas.

Assim, apesar de evidenciar a existência de relações entre a velocidade de embebição, a condição fisiológica e o aumento de volume das sementes, a literatura especializada não explicita as possibilidades de estimativa, do desempenho fisiológico, através da análise das variações de tamanho geradas por hidratações transcorridas com diferentes velocidades em período idêntico. 


\section{MATERIAL E MÉTODOS}

A pesquisa foi conduzida no Laboratório de Análise de Sementes do Departamento de Produção Vegetal da Escola Superior de Agricultura "Luiz de Queiroz" (USP/ESALQ).

Foram empregados três lotes de sementes de soja (cultivar BRS 157), fornecidos pelo Serviço de Produção de Sementes Básicas (SPSB) da Embrapa, constituídos por sementes classificadas pelo tamanho, com base na diferença de espessura, através da passagem em peneiras com crivos oblongos superpostas em ordem decrescente de largura do crivo (15/64, 14/64, $13 / 64,12 / 64,11 / 64$ e 10/64 x 3/4 de polegada), para aproveitamento exclusivo das retidas na peneira com 13/64 x 3/4 de polegada. As sementes, embaladas em papel multifoliado, permaneceram armazenadas em câmara $\left(18-20^{\circ} \mathrm{C}\right.$ e $45 \%$ U.R.) durante o período em que os lotes foram sendo individualmente submetidos, para a caracterização qualitativa inicial, às seguintes avaliações:

3.1 Determinação do grau de umidade: foi determinado utilizando-se o método da estufa de $105^{\circ} \pm 3^{\circ} \mathrm{C} / 24 \mathrm{~h}$ (Brasil, 1992). Os resultados (\%) foram calculados com base no peso úmido (bu).

3.2 Teste de germinação: foi conduzido sob $25^{\circ} \mathrm{C}$, em 50 sementes/repetição, conforme os procedimentos descritos nas Regras para Análise de Sementes (Brasil, 1992). 
3.3 Teste de tetrazólio: foi realizado com 25 sementes/repetição précondicionadas $\left(25^{\circ} \mathrm{C} / 16 \mathrm{~h}\right)$ em papel toalha hidratado. Após o précondicionamento, as sementes foram submersas em solução $(0,075 \%)$ de sal de tetrazólio e mantidas em estufa $\left(35-40^{\circ} \mathrm{C} / 3 \mathrm{~h}\right)$. A seguir, as sementes foram lavadas, drenadas e avaliadas quanto ao vigor segundo os critérios descritos por França Neto et al. (1998).

3.4 Teste de envelhecimento acelerado: foi executado com 50 sementes por repetição, conforme a metodologia descrita por Marcos Filho (1994), empregando caixas gerbox (mini-câmaras) que, após a adição de $40 \mathrm{ml}$ de água no seu interior sob a tela de sustentação das sementes, foram mantidas a $42^{\circ} \mathrm{C} / 48 \mathrm{~h}$. Após este período, as sementes foram submetidas ao teste de germinação, conforme o descrito anteriormente.

3.5 Testes de comprimento da raiz e da plântula: realizados conjuntamente, constaram da instalação de 10 sementes/repetição, no terço superior de papel toalha umedecido com 2,25 vezes o seu peso em água, sob $25^{\circ} \mathrm{C} / 5$ dias em ausência de luz e no interior de saco plástico, conforme as recomendações de Krzyzanowski et al. (1991). Ao final do período, considerando exclusivamente as plântulas normais, foram medidos o comprimento da raiz (ápice da raiz à região de transição com o hipocótilo) e da plântula (ápice da raiz ao ponto de inserção dos cotilédones). Os resultados foram calculados pelo quociente entre o somatório do comprimento (das raízes ou das plântulas) e o número de sementes instaladas.

3.6 Peso de matéria seca da plântula: as plântulas normais, consideradas nas medições do teste de comprimento da plântula, tiveram os cotilédones excluídos e, embaladas em sacos de papel, foram colocadas em estufa (80ํㅡ/24h) com circulação de ar (Marcos Filho et al., 1987). Após este período, 
o peso da matéria seca foi avaliado em balança com precisão de miligrama. Os resultados foram representados pelo quociente entre o peso obtido e o número de sementes instaladas no teste de comprimento da plântula.

3.7 Teste de condutividade elétrica: Amostras de 50 sementes/repetição, previamente pesadas em balança com precisão de 0,01g, foram imersas em 75 $\mathrm{ml}$ de água destilada (25드/24h) para, conforme as indicações de Vieira (1994), ser medida a condutividade elétrica da água de embebição. O resultado, expresso em $\mu \mathrm{mhos} / \mathrm{cm} . g$, foi representado pelo quociente entre a leitura de condutividade e o peso da amostra.

3.8 Teste de emergência de plântulas: realizado em casa de vegetação, foi conduzido com a semeadura de 50 sementes/repetição em mistura umedecida (70\% da capacidade de campo) de terra e areia na proporção de 1:3. A contagem das plântulas emersas foi efetuada aos 14 dias após a instalação.

Após a caracterização dos lotes, as sementes foram retiradas da câmara de armazenamento, com teores de água próximos de $8 \%$, e colocadas em ambiente com $18 \pm 2^{\circ} \mathrm{C}$ e $85 \pm 5 \%$ UR até atingirem, aproximadamente, $13 \%$ de água.

Em seguida, amostras com 400 sementes foram isoladamente distribuídas em rolos com 8 folhas de papel toalha umedecido com água, em volume correspondente a 2,5 vezes o peso do substrato seco, e levadas para germinador $\left(20^{\circ} \mathrm{C}\right)$ durante períodos variáveis $(3,6,9$ e 12 h) de embebição. Após cada um dos períodos de embebição, as sementes foram classificadas por espessura através da utilização de peneiras, com crivos oblongos (16/64, $15 / 64,14 / 64$ e $13 / 64 \times 3 / 4$ de polegada), superpostas em ordem decrescente; foi estimada a freqüência (\%) de indivíduos presentes, em cada espessura, em relação à população de cada amostra submetida à embebição. Em seguida, 
descartada por insuficiência no número de indivíduos a fração retida nos crivos com 16/64 de polegada, as sementes, isoladamente por espessura, foram submetidas aos testes de grau de umidade, germinação, tetrazólio (vigor), comprimentos de raiz e de plântula e peso de matéria seca empregando métodos similares aos descritos para a caracterização qualitativa inicial dos lotes. Para possibilitar as leituras do teste de tetrazólio, as sementes provenientes das embebições de 3 e $6 \mathrm{~h}$ passaram por hidratação complementar até que fossem atingidos graus de umidade iguais ou superiores a 35\%; nos demais períodos de hidratação, este procedimento foi desnecessário.

As determinações foram conduzidas em delineamento inteiramente casualizado com 8 (Tabelas 1 e 2 ) e 24 repetições (Tabela 3). Utilizando o programa Statistical Analisys System (1987), os dados obtidos foram submetidos ao teste de comparação de médias por contrastes (teste F) ao nível de $5 \%$ de probabilidade; quando necessária, foi utilizada a transformação de dados em arc sen $(x / 100)^{0,5}$. Adicionalmente, foram realizadas análises de correlação, entre a freqüência de indivíduos presentes em cada fração classificada, após as embebições, e os testes de avaliação da qualidade fisiológica inicial.

Tabela 1. Esquema de análise de variância adotado para os dados (lotes A, B e C) dos testes de caracterização qualitativa inicial e para os da freqüência de indivíduos presentes em cada espessura após a embebição.

\begin{tabular}{lc}
\hline Causas de variação & Graus de liberdade \\
\hline Lotes & 2 \\
Resíduo & 21 \\
\hline Total & 23 \\
\hline
\end{tabular}


Tabela 2. Esquema de análise de variância empregado por lote para os dados dos testes de avaliação da qualidade fisiológica realizados após a embebição.

\begin{tabular}{lc}
\hline Causas de variação & Graus de liberdade \\
\hline Espessura & 2 \\
Resíduo & 21 \\
\hline Total & 23 \\
\hline
\end{tabular}

Tabela 3. Esquema de análise de variância empregado na análise conjunta dos lotes ( $A, B$ e $C$ ) para os dados dos testes de avaliação da qualidade fisiológica realizados após a embebição.

\begin{tabular}{lc}
\hline Causas de variação & Graus de liberdade \\
\hline Espessura & 2 \\
Resíduo & 69 \\
\hline Total & 71 \\
\hline
\end{tabular}




\section{RESULTADOS E DISCUSSÃO}

Os dados, dos testes de avaliação da qualidade fisiológica inicial (Tabela 4), indicaram, invariavelmente, a presença de diferenciação estatística entre os lotes e, dessa maneira, confirmaram a existência da variação qualitativa requerida pelo método adotado para o estudo. Os lotes, após a classificação por espessura com o aproveitamento exclusivo das sementes com 13/64 de polegada, apresentaram, anteriormente à aplicação dos períodos de embebição, teores médios de água com valores, conforme o desejado, próximos entre si $(12,6 \pm 0,4 \%)$.

Após as embebições, dentro de cada lote e independentemente do período considerado, as sementes tenderam a apresentar incremento do teor de água associado ao aumento da espessura; este fato, excetuando-se o observado nos lotes B e C na embebição de 3h, foi estatisticamente evidenciado (Figuras 1, 2 e 3 ) nas comparações diretas entre as sementes mais espessas (15/64 de polegada) e as menos espessas (13/64 de polegada). Quando examinada a análise conjunta de todos os lotes (Tabela 10), além da superioridade estatística das sementes de 15/64 de polegada em relação às de 13/64 de polegada ocorrer em todos os períodos, as de 14/64 de polegada apresentaram teor de água intermediário aos demais, com significado estatístico, nas embebições mais demoradas (9 e 12h). Dessa forma, confirmando o observado por Kim et al. (1994), os dados indicaram que a variação no teor de água das sementes tendeu a relacionar-se diretamente com a variação da espessura. 
Em todos os lotes e períodos de embebição, a germinação das sementes com 13/64 de polegada superou, em valores absolutos, a das sementes com 15/64 de polegada; observadas as diferenças com significado estatístico, essa superioridade deixou de ocorrer exclusivamente nos lotes C (3h de embebição), B (6h de embebição) e A (9h de embebição), nas análises individualizadas dos lotes (Tabela 5), e foi invariavelmente verificada na análise conjunta (Tabela 10). Este comportamento, admitindo a premissa de que a deterioração favoreça a absorção através da desorganização das membranas celulares (Copeland \& McDonald, 1995; Smith \& Barjak, 1995), indica a possibilidade de que, fixado o período de embebição, as sementes de maior espessura tenham absorvido mais água (Figuras 1, 2 e 3) em decorrência de sua menor qualidade fisiológica (Tabelas 5 e 10). Qualidade fisiológica inferior, em sementes que embeberam mais rapidamente, foi constatada por Rocha et al. (1984) e por Rossetto et al. (1995) em soja e, também, por Souza et al. (1993) em Calopogonium mucunoides. Assim, os dados do teste de germinação sugeriram a existência de relação inversa entre a espessura e a qualidade fisiológica das sementes postas a embeber durante um mesmo período de tempo.

Os dados obtidos no teste de tetrazólio/vigor (Tabela 6) mostraram que, excetuados os casos dos lotes A ( $6 \mathrm{~h}$ de embebição), B ( $9 \mathrm{~h}$ de embebição) e C (12h de embebição), o aumento da espessura esteve, em valores absolutos, associado ao declínio do desempenho. Considerada a análise conjunta dos dados (Tabela 10), a inferioridade das sementes mais espessas (15/64 de polegada), em valores absolutos, sempre ocorreu em relação às demais; estatisticamente, com exceção da ausência de diferenciação proporcionada na embebição de $6 \mathrm{~h}$, as sementes de 15/64 de polegada foram inferiores às sementes com 13/64 de polegada. Assim, concordando com as indicações fornecidas pelo teste de germinação, os dados do teste de tetrazólio/vigor sugeriram a existência de relação inversa entre a espessura e a qualidade fisiológica das sementes embebidas durante períodos equivalentes. 
Os dados dos testes de comprimento da raiz e da plântula apresentaram, em valores absolutos, indicações semelhantes entre si. As sementes mais espessas (15/64 de polegada) tiveram desempenho inferior ao das sementes com 14/64 de polegada, em valores absolutos (Tabelas 7 e 8), na maior parte dos casos; observadas as comparações estatísticas, contudo, os comportamentos verificados não permitiram constatações que evidenciassem diferenças predominantes entre os tratamentos. A análise conjunta (Tabela 10), apesar de confirmar em valores absolutos a inferioridade das sementes com $15 / 64$ de polegada em relação às de 14/64 de polegada, não agregou novas informações à interpretação dos dados. Dessa forma, quando confrontados com as determinações de germinação e de tetrazólio/vigor, os testes de comprimento de raiz e da plântula deixaram de delinear a tendência de inferioridade no desempenho das sementes com 15/64 de polegada em relação às de 13/64 de polegada; contudo, mantiveram as indicações da tendência de inferioridade da maior espessura nas comparações entre as sementes de 15/64 e 14/64 de polegada.

Da mesma forma que o verificado nos testes de comprimento da raiz e da plântula, o teste de peso de matéria seca da plântula não indicou diferenças suficientes para esclarecer, com significado estatístico, tendências nos comportamentos dos tratamentos. Em valores absolutos, com algumas exceções, os dados reforçaram a tendência de inferioridade das sementes mais espessas (15/64 de polegada) nas comparações com as de 14/64 de polegada, tanto na análise individualizada dos lotes (Tabela 9) como na conjunta (Tabela $10)$.

De um modo geral, foram observadas algumas variações entre as informações provenientes das diferentes determinações. Por este motivo, foram compiladas as ocorrências de superioridades (Tabela 11) havidas, entre as sementes com diferentes espessuras, na análise conjunta dos lotes (Tabela 10). A observação da Tabela 11 permite verificar que os dados, quando estatisticamente analisados, nunca acusaram a superioridade das sementes 
com espessura de 15/64 de polegada e, em contrapartida, destacaram a sua inferioridade em relação às sementes com $13 / 64$ de polegada (35\% dos casos), com $14 / 64$ de polegada ( $20 \%$ dos casos) e, adicionalmente, a ambas ( $20 \%$ dos casos). Desconsiderada a análise estatística, e levando em conta os valores absolutos, foram evidenciadas as mesmas inferioridades, porém, em freqüências mais elevadas (respectivamente 70, 95 e 70\% dos casos). Assim, as diferenças predominantes no teste de germinação, ainda que menos acentuadamente nas demais determinações, refletiram a tendência geral dos dados de atribuir desempenho inferior às sementes com espessura de 15/64 de polegada que, fixado o período de embebição, absorveram maior quantidade de água. Ainda de acordo com os dados apresentados na Tabela 11, as freqüências de superioridade, nas comparações entre as sementes com espessuras de 13/64 e 14/64 de polegada, não sugeriram diferenças expressivas entre o comportamento de ambas.

Em complementação à busca de informações relativas às relações entre o processo de embebição e a qualidade fisiológica das sementes, a pesquisa procurou verificar as possibilidades de diferenciação qualitativa, entre lotes, a partir da mensuração das sementes submetidas à hidratação. Para tanto, vencidos os períodos de embebição, foram estimadas, por lote, as freqüências (Tabela 12) de indivíduos existentes em cada uma das espessuras.

O confronto dos dados da qualidade fisiológica inicial dos lotes (Tabela 4), com os das freqüências de indivíduos por espessura após as embebições (Tabela 12), permite verificar, em valores absolutos, que a freqüência das sementes menos espessas (13/64 e 14/64 de polegada), nos períodos de 3, 6 e 9 horas de embebição, foi maior no lote de qualidade fisiológica superior (A); para as sementes mais espessas (15/64 e 16/64 de polegada), considerados os mesmos períodos, as maiores freqüências foram apresentadas pelos lotes de qualidade fisiológica inferior $\left(\begin{array}{lll}B & e & C\end{array}\right)$. Adicionalmente, consideradas as espessuras de 14/64 e 15/64 de polegada, 
constataram-se diferenças significativas, entre todos os lotes, no período de 6 horas de embebição; para a espessura de 14/64 de polegada, a freqüência decresceu do lote $\mathrm{A}$ (maior qualidade fisiológica) para o $\mathrm{C}$ (menor qualidade fisiológica) e, para a espessura de 15/64 de polegada, o comportamento dos dados foi o inverso.

Em apoio a essa constatação, a análise de correlação (Tabela 13) indicou, na embebição de 6 horas, coeficientes invariavelmente iguais ou superiores a 0,65 nos confrontos entre as freqüências das espessuras 14/64 e 15/64 de polegada e os dados provenientes dos testes de avaliação da qualidade fisiológica inicial.

Desse modo, marcadamente no período de 6 horas, houve similaridade estatística, na diferenciação dos lotes, entre os dados de desempenho fisiológico e os dados de distribuição da espessura nas sementes embebidas.

\subsection{Considerações gerais}

Fixado o período de embebição, as diferenças havidas no teor de água tenderam a ser acompanhadas por variações de mesmo sentido na espessura. Foi adicionalmente observada, de modo mais evidente nos testes de germinação e de tetrazólio/vigor, a existência de relação inversa entre a espessura e o desempenho fisiológico das sementes.

Estes fatos, quando realizada a comparação de lotes, pareceram justificar a correspondência verificada entre as estimativas de qualidade fisiológica e as freqüências de espessura em sementes hidratadas. 
Espessuras:

$\square 13 / 64$

$\square 14 / 64$

$\square 15 / 64$

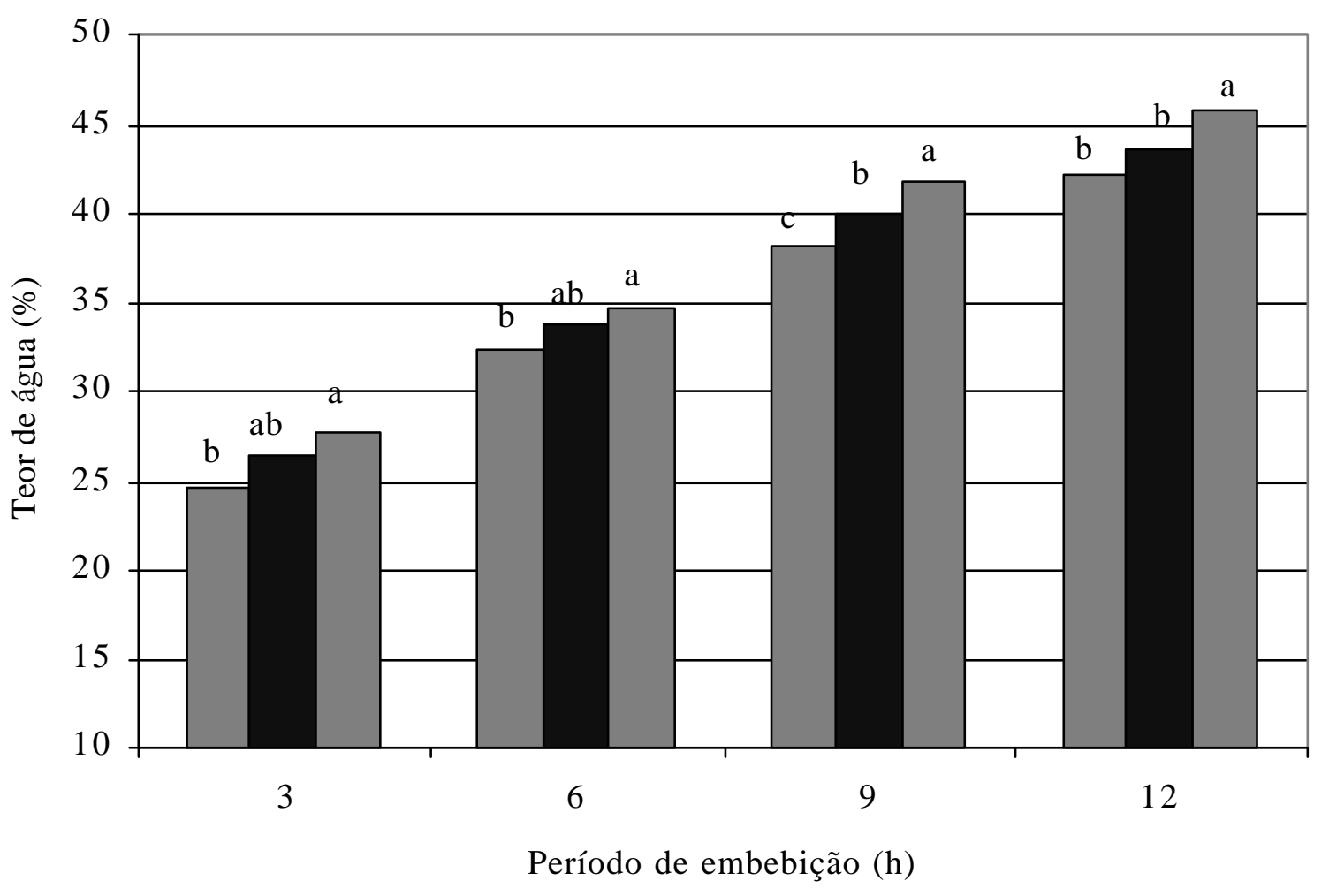

Figura 1 - Dados de teor de água (\%) obtidos em sementes de soja (lote A) classificadas por espessura após a aplicação de períodos (3, 6, 9 e $12 \mathrm{~h})$ de embebição. Médias seguidas de mesma letra, dentro de cada período de embebição, não diferem estatisticamente entre si $(p \leq 0,05)$. 
Espessuras: $\square 13 / 64 \quad \square 14 / 64 \quad \square 15 / 64$

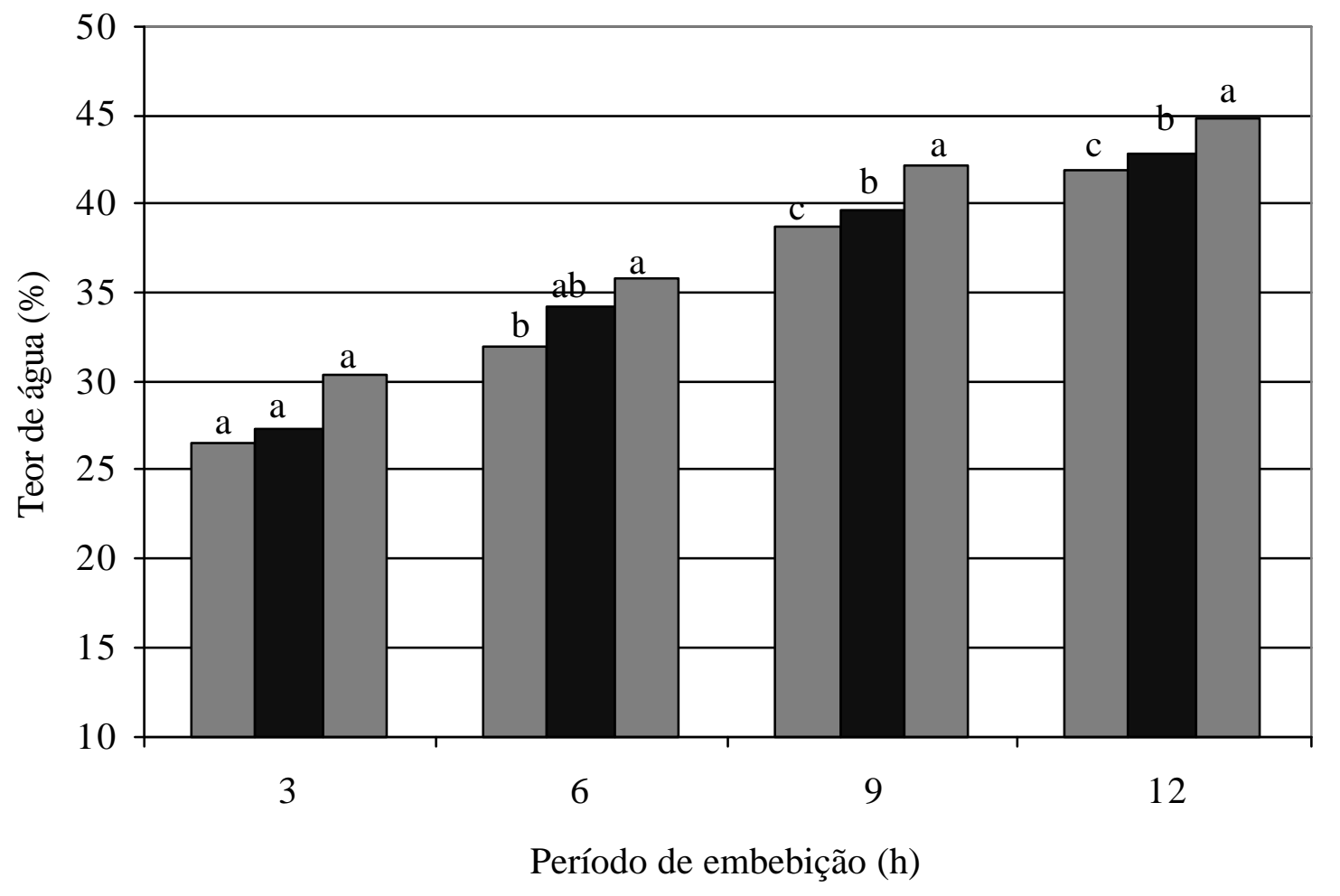

Figura 2 - Dados de teor de água (\%) obtidos em sementes de soja (lote B) classificadas por espessura após a aplicação de períodos $(3,6,9$ e 12h) de embebição. Médias seguidas de mesma letra, dentro de cada período de embebição, não diferem estatisticamente entre si $(p \leq 0,05)$. 

Espessuras:
$\square 13 / 64$
$\mathbf{1 4 / 6 4}$
$15 / 64$

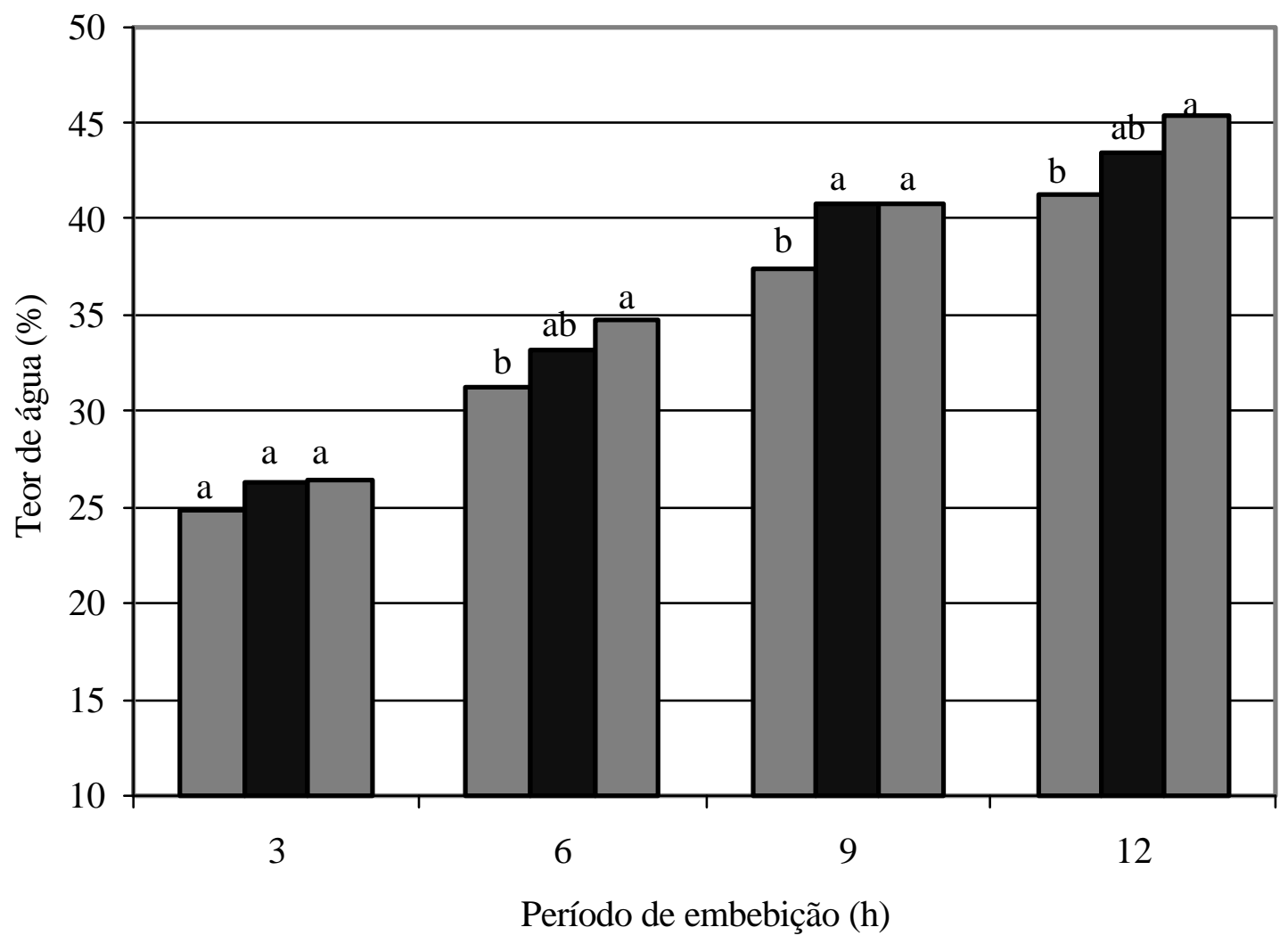

Período de embebição (h)

Figura 3 - Dados de teor de água (\%) obtidos em sementes de soja (lote C) classificadas por espessura após a aplicação de períodos $(3,6,9$ e 12h) de embebição. Médias seguidas de mesma letra, dentro de cada período de embebição, não diferem estatisticamente entre si $(p \leq 0,05)$. 
Tabela 4. Dados da qualidade fisiológica inicial dos lotes $A, B$ e $C$ avaliada pelos testes de germinação (G), de envelhecimento artificial (EA), de tetrazólio/vigor (TZ), de comprimentos da raiz (CR) e da plântula (CP), de peso matéria seca da plântula (MS), de condutividade elétrica $(C)$ e de emergência de plântula (E).

\begin{tabular}{|c|c|c|c|c|c|c|c|c|}
\hline \multirow[b]{2}{*}{ Lotes } & \multicolumn{8}{|c|}{ Testes } \\
\hline & $\mathrm{G}(\%)$ & EA (\%) & TZ (\%) & $\mathrm{CR}(\mathrm{cm})$ & $\mathrm{CP}(\mathrm{cm})$ & $\mathrm{MS}$ (mg ) & $\mathrm{C}(\mu \mathrm{mhos} / \mathrm{cm} . \mathrm{g})$ & $E(\%)$ \\
\hline$A$ & 93 a & $75 \mathrm{a}$ & $82 \mathrm{a}$ & $10,5 a$ & $16,5 \mathrm{a}$ & $21,6 a$ & $77,1 \mathrm{a}$ & $86 a$ \\
\hline B & $86 \mathrm{~b}$ & $63 \mathrm{~b}$ & $67 \mathrm{~b}$ & $6,1 \mathrm{~b}$ & $10,8 b$ & $17,9 \mathrm{~b}$ & $83,5 b$ & $63 \mathrm{~b}$ \\
\hline $\mathrm{C}$ & $76 \mathrm{c}$ & $53 \mathrm{c}$ & $59 \mathrm{c}$ & $3,8 \mathrm{c}$ & $7,6 \mathrm{c}$ & $12,1 \mathrm{c}$ & $99,5 \mathrm{c}$ & $47 c$ \\
\hline
\end{tabular}

Médias seguidas de mesma letra nas colunas não diferem estatisticamente entre si $(p \leq 0,05)$ 
Tabela 5. Dados de germinação (\%) obtidos em sementes de soja (lotes A, B e C) classificadas por espessura após a aplicação dos períodos (3, 6, 9 e 12h) de embebição.

\begin{tabular}{|c|c|c|c|c|c|c|c|c|c|c|c|c|}
\hline \multirow[b]{4}{*}{ Lotes } & \multicolumn{12}{|c|}{ Períodos de embebição } \\
\hline & \multicolumn{3}{|c|}{$3 h$} & \multicolumn{3}{|c|}{$6 \mathrm{~h}$} & \multicolumn{3}{|c|}{$9 \mathrm{~h}$} & \multicolumn{3}{|c|}{$12 \mathrm{~h}$} \\
\hline & \multicolumn{3}{|c|}{ Espessuras (polegada) } & \multicolumn{3}{|c|}{ Espessuras (polegada) } & \multicolumn{3}{|c|}{ Espessuras (polegada) } & \multicolumn{3}{|c|}{ Espessuras (polegada) } \\
\hline & $13 / 64$ & $14 / 64$ & $15 / 64$ & $13 / 64$ & $14 / 64$ & $15 / 64$ & $13 / 64$ & $14 / 64$ & $15 / 64$ & $13 / 64$ & $14 / 64$ & $15 / 64$ \\
\hline$A$ & $94 \mathrm{a}$ & $96 \mathrm{a}$ & $85 \mathrm{~b}$ & $98 \mathrm{a}$ & $92 \mathrm{~b}$ & $90 \mathrm{~b}$ & $92 \mathrm{~b}$ & $96 \mathrm{a}$ & $91 \mathrm{~b}$ & $93 \mathrm{a}$ & $92 \mathrm{a}$ & $88 \mathrm{~b}$ \\
\hline$B$ & $94 \mathrm{a}$ & $87 \mathrm{~b}$ & $87 \mathrm{~b}$ & $89 a b$ & $91 \mathrm{a}$ & $85 \mathrm{~b}$ & $94 \mathrm{a}$ & $89 \mathrm{~b}$ & $89 \mathrm{~b}$ & $92 \mathrm{a}$ & $90 \mathrm{a}$ & $83 \mathrm{~b}$ \\
\hline C & $80 \mathrm{a}$ & $83 \mathrm{a}$ & $79 \mathrm{a}$ & $86 \mathrm{a}$ & $86 \mathrm{a}$ & $77 \mathrm{~b}$ & $83 a$ & $79 a b$ & $77 \mathrm{~b}$ & $86 \mathrm{a}$ & $84 \mathrm{a}$ & $75 \mathrm{~b}$ \\
\hline
\end{tabular}

Médias seguidas de mesma letra nas linhas, dentro de cada período de embebição, não diferem estatisticamente entre si $(p \leq 0,05)$ 
Tabela 6. Dados de tetrazólio/vigor (\%) obtidos em sementes de soja (lotes A, B e C) classificadas por espessura após a aplicação dos períodos (3, 6, 9 e 12h) de embebição.

\begin{tabular}{|c|c|c|c|c|c|c|c|c|c|c|c|c|}
\hline \multirow[b]{4}{*}{ Lotes } & \multicolumn{12}{|c|}{ Períodos de embebição } \\
\hline & \multicolumn{3}{|c|}{$3 h$} & \multicolumn{3}{|c|}{$6 h$} & \multicolumn{3}{|c|}{$9 \mathrm{~h}$} & \multicolumn{3}{|c|}{$12 \mathrm{~h}$} \\
\hline & \multicolumn{3}{|c|}{ Espessuras (polegada) } & \multicolumn{3}{|c|}{ Espessuras (polegada) } & \multicolumn{3}{|c|}{ Espessuras (polegada) } & \multicolumn{3}{|c|}{ Espessuras (polegada) } \\
\hline & $13 / 64$ & $14 / 64$ & $15 / 64$ & $13 / 64$ & $14 / 64$ & $15 / 64$ & $13 / 64$ & $14 / 64$ & $15 / 64$ & $13 / 64$ & $14 / 64$ & $15 / 64$ \\
\hline$A$ & $87 \mathrm{a}$ & $80 \mathrm{~b}$ & $79 \mathrm{~b}$ & $83 \mathrm{a}$ & 83 a & $76 \mathrm{~b}$ & 83 a & $75 \mathrm{~b}$ & $66 \mathrm{c}$ & 83 a & $80 \mathrm{a}$ & $62 \mathrm{~b}$ \\
\hline $\mathrm{B}$ & $74 \mathrm{a}$ & $73 a b$ & $64 \mathrm{~b}$ & 72 a & $71 \mathrm{a}$ & $70 \mathrm{a}$ & 68 a & $65 \mathrm{a}$ & $68 \mathrm{a}$ & $75 \mathrm{a}$ & $74 \mathrm{a}$ & $62 \mathrm{~b}$ \\
\hline C & $61 \mathrm{a}$ & $59 a$ & 56 a & 63 a & $62 \mathrm{a}$ & $61 \mathrm{a}$ & $65 a$ & $63 \mathrm{a}$ & $58 \mathrm{a}$ & $65 a$ & $67 \mathrm{a}$ & $56 \mathrm{~b}$ \\
\hline
\end{tabular}

Médias seguidas de mesma letra nas linhas, dentro de cada período de embebição, não diferem estatisticamente entre si $(p \leq 0,05)$ 
Tabela 7. Dados de comprimento $(\mathrm{cm})$ da raiz obtidos em sementes de soja (lotes A, B e C) classificadas por espessura após a aplicação dos períodos (3, 6, 9 e 12h) de embebição.

\begin{tabular}{|c|c|c|c|c|c|c|c|c|c|c|c|c|}
\hline \multirow[b]{4}{*}{ Lotes } & \multicolumn{12}{|c|}{ Períodos de embebição } \\
\hline & \multicolumn{3}{|c|}{$3 h$} & \multicolumn{3}{|c|}{$6 h$} & \multicolumn{3}{|c|}{$9 h$} & \multicolumn{3}{|c|}{$12 \mathrm{~h}$} \\
\hline & \multicolumn{3}{|c|}{ Espessuras (polegada) } & \multicolumn{3}{|c|}{ Espessuras (polegada) } & \multicolumn{3}{|c|}{ Espessuras (polegada) } & \multicolumn{3}{|c|}{ Espessuras (polegada) } \\
\hline & $13 / 64$ & $14 / 64$ & $15 / 64$ & $13 / 64$ & $14 / 64$ & $15 / 64$ & $13 / 64$ & $14 / 64$ & $15 / 64$ & $13 / 64$ & $14 / 64$ & $15 / 64$ \\
\hline$A$ & $9,6 \mathrm{~b}$ & $11,8 \mathrm{a}$ & $10,8 a b$ & $8,8 \mathrm{a}$ & $8,1 a b$ & $7,7 \mathrm{~b}$ & $7,8 \mathrm{a}$ & $7,4 \mathrm{a}$ & $7,1 \mathrm{a}$ & $5,3 \mathrm{a}$ & 5,9 a & $5,8 \mathrm{a}$ \\
\hline $\mathrm{B}$ & $5,5 \mathrm{a}$ & $6,1 \mathrm{a}$ & $5,4 \mathrm{a}$ & $6,5 \mathrm{a}$ & $6,0 \mathrm{a}$ & $5,8 \mathrm{a}$ & $7,8 \mathrm{~b}$ & $9,0 \mathrm{a}$ & $8,1 a b$ & $6,9 \mathrm{~b}$ & $8,0 \mathrm{a}$ & $7,5 a b$ \\
\hline C & $5,8 \mathrm{a}$ & $5,6 \mathrm{a}$ & $6,5 \mathrm{a}$ & $3,9 \mathrm{a}$ & $4,1 \mathrm{a}$ & $3,8 \mathrm{a}$ & $5,0 \mathrm{a}$ & $4,9 \mathrm{a}$ & $4,7 \mathrm{a}$ & $4,7 \mathrm{~b}$ & $5,4 \mathrm{a}$ & $4,6 \mathrm{~b}$ \\
\hline
\end{tabular}

Médias seguidas de mesma letra nas linhas, dentro de cada período de embebição, não diferem estatisticamente entre si $(p \leq 0,05)$ 
Tabela 8. Dados de comprimento $(\mathrm{cm})$ da plântula obtidos em sementes de soja (lotes A, B e C) classificadas por espessura após a aplicação dos períodos (3, 6, 9 e 12h) de embebição.

\begin{tabular}{|c|c|c|c|c|c|c|c|c|c|c|c|c|}
\hline \multirow[b]{4}{*}{ Lotes } & \multicolumn{12}{|c|}{ Períodos de embebição } \\
\hline & \multicolumn{3}{|c|}{$3 h$} & \multicolumn{3}{|c|}{$6 \mathrm{~h}$} & \multicolumn{3}{|c|}{$9 \mathrm{~h}$} & \multicolumn{3}{|c|}{$12 \mathrm{~h}$} \\
\hline & \multicolumn{3}{|c|}{ Espessuras (polegada) } & \multicolumn{3}{|c|}{ Espessuras (polegada) } & \multicolumn{3}{|c|}{ Espessuras (polegada) } & \multicolumn{3}{|c|}{ Espessuras (polegada) } \\
\hline & $13 / 64$ & $14 / 64$ & $15 / 64$ & $13 / 64$ & $14 / 64$ & $15 / 64$ & $13 / 64$ & $14 / 64$ & $15 / 64$ & $13 / 64$ & $14 / 64$ & $15 / 64$ \\
\hline$A$ & $15,0 \mathrm{~b}$ & $18,5 \mathrm{a}$ & $16,9 a b$ & $14,9 \mathrm{a}$ & $14,3 a b$ & $13,2 b$ & $14,6 \mathrm{a}$ & $13,9 a b$ & $12,9 \mathrm{~b}$ & $10,4 \mathrm{a}$ & $11,7 \mathrm{a}$ & $11,6 \mathrm{a}$ \\
\hline$B$ & $10,3 \mathrm{a}$ & $11,3 \mathrm{a}$ & $9,9 \mathrm{a}$ & $12,2 \mathrm{a}$ & $11,5 \mathrm{a}$ & $11,1 \mathrm{a}$ & $13,5 b$ & $15,1 \mathrm{a}$ & $13,8 a b$ & $12,2 \mathrm{~b}$ & $13,9 \mathrm{a}$ & $12,6 a b$ \\
\hline $\mathrm{C}$ & $10,0 \mathrm{a}$ & $9,7 \mathrm{a}$ & $11,0 \mathrm{a}$ & $7,7 \mathrm{a}$ & $8,1 \mathrm{a}$ & $7,6 \mathrm{a}$ & $9,5 \mathrm{a}$ & $9,0 \mathrm{a}$ & $8,7 \mathrm{a}$ & $9,1 \mathrm{~b}$ & $10,3 \mathrm{a}$ & $8,8 \mathrm{~b}$ \\
\hline
\end{tabular}

Médias seguidas de mesma letra nas linhas, dentro de cada período de embebição, não diferem estatisticamente entre si $(p \leq 0,05)$ 
Tabela 9. Dados do peso $(\mathrm{mg})$ de matéria seca da plântula obtidos em sementes de soja (lotes A, B e C) classificadas por espessura após a aplicação dos períodos (3, 6, 9 e 12h) de embebição.

\begin{tabular}{|c|c|c|c|c|c|c|c|c|c|c|c|c|}
\hline \multirow[b]{4}{*}{ Lotes } & \multicolumn{12}{|c|}{ Períodos de embebição } \\
\hline & \multicolumn{3}{|c|}{$3 h$} & \multicolumn{3}{|c|}{$6 \mathrm{~h}$} & \multicolumn{3}{|c|}{$9 \mathrm{~h}$} & \multicolumn{3}{|c|}{$12 \mathrm{~h}$} \\
\hline & \multicolumn{3}{|c|}{ Espessuras (polegada) } & \multicolumn{3}{|c|}{ Espessuras (polegada) } & \multicolumn{3}{|c|}{ Espessuras (polegada) } & \multicolumn{3}{|c|}{ Espessuras (polegada) } \\
\hline & $13 / 64$ & $14 / 64$ & $15 / 64$ & $13 / 64$ & $14 / 64$ & $15 / 64$ & $13 / 64$ & $14 / 64$ & $15 / 64$ & $13 / 64$ & $14 / 64$ & $15 / 64$ \\
\hline$A$ & $19,9 \mathrm{~b}$ & $24,1 \mathrm{a}$ & $22,0 a b$ & $19,8 \mathrm{a}$ & $19,7 \mathrm{a}$ & $18,0 \mathrm{~b}$ & $21,2 \mathrm{a}$ & $20,8 \mathrm{a}$ & $19,4 \mathrm{a}$ & $15,0 \mathrm{a}$ & $16,8 \mathrm{a}$ & $16,5 \mathrm{a}$ \\
\hline$B$ & $16,0 \mathrm{a}$ & $14,5 \mathrm{a}$ & $15,1 \mathrm{a}$ & $16,3 \mathrm{a}$ & $16,0 \mathrm{a}$ & $15,5 \mathrm{a}$ & $21,0 \mathrm{a}$ & $22,6 \mathrm{a}$ & $21,4 \mathrm{a}$ & $17,9 \mathrm{a}$ & $20,7 \mathrm{a}$ & $18,3 \mathrm{a}$ \\
\hline C & $14,0 \mathrm{a}$ & $14,1 \mathrm{a}$ & $16,6 \mathrm{a}$ & $11,3 \mathrm{a}$ & $11,6 \mathrm{a}$ & $11,0 \mathrm{a}$ & $13,5 \mathrm{a}$ & $12,8 \mathrm{a}$ & $13,6 \mathrm{a}$ & $13,0 \mathrm{~b}$ & $15,8 \mathrm{a}$ & $14,2 a b$ \\
\hline
\end{tabular}

Médias seguidas de mesma letra nas linhas, dentro de cada período de embebição, não diferem estatisticamente entre si $(p \leq 0,05)$ 
Tabela 10. Análise conjunta (lotes $A, B$ e $C$ ): dados do teor de água (TA), germinação (G), tetrazólio/vigor (TZ), comprimentos da raiz $(C R)$ e da plântula $(C P)$ e peso de matéria seca da plântula (MS) obtidos em sementes de soja classificadas por espessura após a aplicação dos períodos (3, 6, 9 e 12h) de embebição.

\begin{tabular}{|c|c|c|c|c|c|c|c|c|c|c|c|c|}
\hline \multirow[b]{4}{*}{ Lotes } & \multicolumn{12}{|c|}{ Períodos de embebição } \\
\hline & \multicolumn{3}{|c|}{$3 h$} & \multicolumn{3}{|c|}{$6 \mathrm{~h}$} & \multicolumn{3}{|c|}{$9 \mathrm{~h}$} & \multicolumn{3}{|c|}{$12 \mathrm{~h}$} \\
\hline & \multicolumn{3}{|c|}{ Espessuras (polegada) } & \multicolumn{3}{|c|}{ Espessuras (polegada) } & \multicolumn{3}{|c|}{ Espessuras (polegada) } & \multicolumn{3}{|c|}{ Espessuras (polegada) } \\
\hline & $13 / 64$ & $14 / 64$ & $15 / 64$ & $13 / 64$ & $14 / 64$ & $15 / 64$ & $13 / 64$ & $14 / 64$ & $15 / 64$ & $13 / 64$ & $14 / 64$ & $15 / 64$ \\
\hline TA (\%) & $25,3 \mathrm{~b}$ & $26,7 a b$ & $28,1 \mathrm{a}$ & $31,9 \mathrm{~b}$ & $34,3 \mathrm{a}$ & $35,0 \mathrm{a}$ & $38,1 \mathrm{c}$ & $40,2 \mathrm{~b}$ & $41,6 \mathrm{a}$ & $41,8 \mathrm{c}$ & $43,2 \mathrm{~b}$ & $45,4 \mathrm{a}$ \\
\hline G (\%) & $90 \mathrm{a}$ & $89 a$ & $84 \mathrm{~b}$ & $92 \mathrm{a}$ & $90 \mathrm{a}$ & $85 \mathrm{~b}$ & $90 \mathrm{a}$ & $89 a b$ & $85 b$ & $91 \mathrm{a}$ & $89 a$ & $82 \mathrm{~b}$ \\
\hline TZ (\%) & $74 \mathrm{a}$ & $71 a b$ & $67 \mathrm{~b}$ & $73 \mathrm{a}$ & $72 \mathrm{a}$ & $69 a$ & $72 \mathrm{a}$ & $68 a b$ & $64 \mathrm{~b}$ & $74 \mathrm{a}$ & $74 \mathrm{a}$ & $60 \mathrm{~b}$ \\
\hline $\mathrm{CR}(\mathrm{cm})$ & $6,9 \mathrm{a}$ & $7,8 \mathrm{a}$ & 7,6 a & $6,4 \mathrm{a}$ & $6,0 \mathrm{a}$ & $5,7 \mathrm{a}$ & $6,9 a$ & $7,1 \mathrm{a}$ & $6,6 \mathrm{a}$ & $5,6 \mathrm{~b}$ & $6,5 \mathrm{a}$ & $5,9 a b$ \\
\hline $\mathrm{CP}(\mathrm{cm})$ & $11,8 \mathrm{a}$ & $13,2 \mathrm{a}$ & $12,6 \mathrm{a}$ & $11,6 \mathrm{a}$ & $11,3 \mathrm{a}$ & $10,7 \mathrm{a}$ & $12,5 \mathrm{a}$ & $12,7 \mathrm{a}$ & $11,8 \mathrm{a}$ & $10,6 b$ & $12,0 \mathrm{a}$ & $11,0 a b$ \\
\hline $\mathrm{MS}(\mathrm{mg})$ & $16,6 \mathrm{a}$ & $17,6 \mathrm{a}$ & $17,9 a$ & $15,8 \mathrm{a}$ & $15,8 \mathrm{a}$ & $14,8 \mathrm{a}$ & $18,6 \mathrm{a}$ & $18,7 \mathrm{a}$ & $18,1 \mathrm{a}$ & $15,3 \mathrm{~b}$ & $17,8 \mathrm{a}$ & $16,3 \mathrm{ab}$ \\
\hline
\end{tabular}

Médias seguidas de mesma letra nas linhas, dentro de cada período de embebição, não diferem estatisticamente entre si $(p \leq 0,05)$ 
Tabela 11. Ocorrências de superioridades, entre as sementes com diferentes espessuras, verificadas nos testes de avaliação da qualidade fisiológica realizados após os períodos de embebição: número e freqüência (\%), obtidos num total de 20 possibilidades (5 testes em 4 períodos de embebição), considerando a análise conjunta dos lotes (Tabela 10) segundo interpretações baseadas em critério estatístico e em valores absolutos.

\begin{tabular}{|c|c|c|c|c|}
\hline \multirow{2}{*}{$\begin{array}{c}\text { Espessuras } \\
\text { (64 avos de polegada) }\end{array}$} & \multicolumn{2}{|c|}{ Critério Estatístico } & \multicolumn{2}{|c|}{ Valores Absolutos } \\
\hline & Número & Freqüência (\%) & Número & Freqüência (\%) \\
\hline $13>14$ & 0 & 0 & 9 & 45 \\
\hline $13>15$ & 7 & 35 & 14 & 70 \\
\hline $13>14$ e 15 & 0 & 0 & 9 & 45 \\
\hline $14>13$ & 3 & 15 & 9 & 45 \\
\hline $14>15$ & 4 & 20 & 19 & 95 \\
\hline $14>13$ e 15 & 0 & 0 & 8 & 40 \\
\hline $15>13$ & 0 & 0 & 6 & 30 \\
\hline $15>14$ & 0 & 0 & 1 & 5 \\
\hline $15>13$ e 14 & 0 & 0 & 1 & 5 \\
\hline 13 e $14>15$ & 4 & 20 & 14 & 70 \\
\hline 13 e $15>14$ & 0 & 0 & 0 & 0 \\
\hline 14 e $15>13$ & 0 & 0 & 6 & 30 \\
\hline
\end{tabular}


Tabela 12. Dados de freqüência (\%) da presença, por espessura, de sementes de soja (lotes A, B e C) classificadas após a aplicação dos períodos (3, 6, 9 e 12 h) de embebição.

\begin{tabular}{|c|c|c|c|c|c|c|c|c|c|c|c|c|c|c|c|c|}
\hline \multirow[b]{4}{*}{ Lotes } & \multicolumn{16}{|c|}{ Períodos de embebição } \\
\hline & \multicolumn{4}{|c|}{$3 \mathrm{~h}$} & \multicolumn{4}{|c|}{$6 \mathrm{~h}$} & \multicolumn{4}{|c|}{$9 h$} & \multicolumn{4}{|c|}{$12 \mathrm{~h}$} \\
\hline & \multicolumn{4}{|c|}{ Espessuras (polegada) } & \multicolumn{4}{|c|}{ Espessuras (polegada) } & \multicolumn{4}{|c|}{ Espessuras (polegada) } & \multicolumn{4}{|c|}{ Espessuras (polegada) } \\
\hline & $13 / 64$ & $14 / 64$ & $15 / 64$ & $16 / 64$ & $13 / 64$ & $14 / 64$ & $15 / 64$ & $16 / 64$ & $13 / 64$ & $14 / 64$ & $15 / 64$ & $16 / 64$ & $13 / 64$ & $14 / 64$ & $15 / 64$ & $16 / 64$ \\
\hline$A$ & $15,5 \mathrm{a}$ & $53,8 \mathrm{a}$ & $27,6 \mathrm{~b}$ & $3,1 \mathrm{~b}$ & $14,1 \mathrm{a}$ & $52,5 \mathrm{a}$ & $30,2 \mathrm{c}$ & $3,2 b$ & $22,2 \mathrm{a}$ & $59,9 a$ & $17,6 \mathrm{~b}$ & $0,3 \mathrm{~b}$ & 26,9 a & $61,3 \mathrm{~b}$ & $11,8 a b$ & $0,0 \mathrm{a}$ \\
\hline $\mathrm{B}$ & $12,6 \mathrm{~b}$ & $48,2 \mathrm{~b}$ & $32,8 \mathrm{a}$ & $6,4 \mathrm{a}$ & $10,1 \mathrm{c}$ & $49,2 \mathrm{~b}$ & $35,0 \mathrm{~b}$ & $5,7 \mathrm{a}$ & $16,9 b$ & $55,8 \mathrm{~b}$ & $26,3 \mathrm{a}$ & $1,0 \mathrm{a}$ & $24,8 a b$ & $63,9 \mathrm{a}$ & $11,2 b$ & $0,1 \mathrm{a}$ \\
\hline $\mathrm{C}$ & $11,5 b$ & $52,4 \mathrm{a}$ & $32,4 \mathrm{a}$ & $3,7 \mathrm{~b}$ & $12,1 \mathrm{~b}$ & $43,8 \mathrm{c}$ & $38,8 \mathrm{a}$ & $5,3 \mathrm{a}$ & $18,1 \mathrm{~b}$ & $58,0 \mathrm{a}$ & $23,4 \mathrm{a}$ & $0,5 \mathrm{~b}$ & $23,0 \mathrm{~b}$ & $64,2 \mathrm{a}$ & $12,7 \mathrm{a}$ & $0,1 \mathrm{a}$ \\
\hline
\end{tabular}

Médias seguidas de mesma letra nas colunas não diferem estatisticamente entre si $(p \leq 0,05)$ 
Tabela 13. Coeficientes de correlação entre as freqüências (\%) de presença de sementes, por espessura (Tabela 12), e os testes de germinação (G), de envelhecimento artificial (EA), de tetrazólio/vigor (TZ), de comprimentos da raiz (CR) e da plântula (CP), de peso de matéria seca da plântula (MS), de condutividade elétrica (C) e de emergência de plântulas (E) aplicados para a estimativa da qualidade fisiológica inicial dos lotes (Tabela 4).

\begin{tabular}{|c|c|c|c|c|c|c|c|c|c|}
\hline $\begin{array}{l}\text { Períodos } \\
\text { embebição }\end{array}$ & $\begin{array}{l}\text { Espessura } \\
\text { (polegada) }\end{array}$ & $\mathrm{G}$ & EA & $\mathrm{TZ}$ & $\mathrm{CR}$ & $\mathrm{CP}$ & MS & C & $E$ \\
\hline \multirow{3}{*}{$3 \mathrm{~h}$} & $13 / 64$ & 0,4 & 0,39 & 0,44 * & 0,61 ** & $0,58^{* *}$ & 0,50 * & (-) 0,43 * & 0,65 ** \\
\hline & $14 / 64$ & 0,37 & 0,13 & 0,26 & 0,18 & 0,18 & 0,03 & 0,06 & 0,27 \\
\hline & $15 / 64$ & (-) 0,45 * & (-) 0,35 & (-) 0,53 ** & (-) 0,53 ** & (-) 0,49 * & (-) 0,38 & 0,35 & (-) 0,60 ** \\
\hline \multirow{3}{*}{$6 \mathrm{~h}$} & $13 / 64$ & 0,3 & 0,44 * & 0,29 & 0,37 & 0,37 & 0,28 & $(-) 0,47^{*}$ & 0,42 * \\
\hline & $14 / 64$ & $0,71^{\star *}$ & $0,65^{* *}$ & $0,81^{* *}$ & 0,81 ** & 0,79 ** & $0,74^{* *}$ & (-) 0,70 ** & 0,76 ** \\
\hline & $15 / 64$ & (-) 0,76 ** & (-) $0,75^{* *}$ & (-) 0,74 ** & $(-) 0,84^{* *}$ & (-) $0,83^{* *}$ & (-) $0,73^{* *}$ & 0,81 ** & (-) 0,79 ** \\
\hline \multirow{3}{*}{$9 \mathrm{~h}$} & $13 / 64$ & 0,27 & 0,38 & 0,52 ** & 0,42 * & 0,41 * & 0,26 & (-) 0,21 & 0,44 * \\
\hline & $14 / 64$ & 0,38 & 0,24 & $0,41^{*}$ & 0,16 & 0,11 & 0,17 & (-) 0,34 & 0,28 \\
\hline & $15 / 64$ & (-) 0,42 * & (-) 0,39 & $(-) 0,57^{* *}$ & (-) 0,36 & (-) 0,33 & (-) 0,26 & 0,37 & (-) $0,45^{*}$ \\
\hline \multirow{3}{*}{$12 \mathrm{~h}$} & $13 / 64$ & 0,51 * & 0,28 & 0,56 ** & $0,57^{* *}$ & $0,57^{* *}$ & 0,34 & (-) 0,42 * & $0,64^{* *}$ \\
\hline & $14 / 64$ & (-) 0,54 ** & (-) 0,21 & (-) $0,57^{* *}$ & (-) 0,42 * & (-) 0,42 * & (-) 0,25 & 0,26 & (-) 0,54 ** \\
\hline & $15 / 64$ & $(-) 0.1$ & (-) 0,2 & (-) 0,06 & (-) 0,32 & (-) 0,33 & (-) 0,20 & 0,33 & (-) 0,26 \\
\hline
\end{tabular}

* - significativo a $5 \%$ de probabilidade ${ }^{* *}$ - significativo a $1 \%$ de probabilidade 


\title{
5 CONCLUSÕES
}

\author{
A qualidade fisiológica afeta o teor de água e a espessura \\ alcançados pelas sementes de soja durante a embebição. Assim, há a \\ possibilidade de comparar o desempenho fisiológico relativo de lotes por \\ intermédio dos dados de freqüência de espessura em sementes hidratadas.
}




\section{REFERÊNCIAS BIBLIOGRÁFICAS}

ARANTES, H.A.G.; ROCHA, V.S.; SILVA, E.A.M. SEDIYAMA, T. Espessura do tegumento, embebição em água e qualidade fisiológica da semente de soja (Glycine max (L.) Merril). Revista Ceres, v.41, n.234, p.126-132, 1994.

ARMSTRONG, H.; McDONALD, M.B. Effects of osmoconditioning on water uptake and electrical conductivity in soybean seeds. Seed Science and Technology, v.20, n.3, p.391-400, 1992.

BEWLEY, J.D. ; BLACK, M. Seeds: Physiology of development and germination. 2.ed. New York: Plenum Press, 1994. 445 p.

BLACKLOW, W.M. Mathematical description of the influence of temperature and seed quality on imbibition by seeds of corn (Zea mays L.). Crop Science, v.12, n.5, p.643-646, 1972.

BRADFORD, K. J. Water relations in seed germination. In: KIGEL, Y.; GALILI, G. (Ed.) Seed development and germination. New York: Marcel Dekker, 1995. cap.3, p. 351-356.

BRASIL. Ministério da Agricultura. Secretaria Nacional de Defesa Agropecuária. Regras para análise de sementes. Brasília, 1992. 365 p. 
CALERO, E.; WEST, S.H.; HINSON, K. Water absortion of soybean seeds and associated causal factors. Crop Science, v.21, n.6, p.926-933, 1981.

CARVALHO, N.M.; NAKAGAWA, J. Sementes: ciência, tecnologia e produção. 3. ed. Campinas: Fundação Cargill, 1988. 424 p.

CHING, T.M. Metabolism of germinating seeds. In: KOSLOWSKI, T.T. (Ed.) Seed biology. New York: Academic Press, 1972. cap.2, p.103-218.

CLARKE, J.M.; DePAUW, R.M. Water imbibition rate of wheat kernels as affected by kernel color, weather damage and method of treshing. Canadian Journal of Plant Science, v.69, n.1, p.1-7, 1989.

COPELAND, L.O.; McDONALD, M.B. Principles of seed science and technology. 3. ed. New York : Chapman \& Hall, 1995. 409 p.

FRANÇA NETO, J.B.; KRZYZANOWSKI, F.C.; COSTA, N.P. 0 teste de tetrazólio em sementes de soja. Londrina: EMBRAPA, CNPSo, 1998. 72p. (EMBRAPA, CNPSo. Documentos, 116).

HEGARTY, T.W. The physiology of seed hydratation and dehydratation, and the relation between water stress and the control of germination: a review. Plant, Cell and Environment, v.1, n.1, p.101-119, 1978.

HOBBS, P.R.; OBENDORF, R.L. Interaction of initial seed moisture and imbibitional temperature on germination and productivity of soybean. Crop Science, v.13, n.5, p.664-667, 1972. 
KIM, Y.H.; KIM, S.D.; HONG, E.H. Properties of soybean seeds during hydration. Journal of Agricultural Science, Upland and Industrial Crops, v.36, n.1, p.71-75, 1994. /Resumo em CAB Abstracts on CD ROM, 1995/.

KRZYZANOWSKI, F.C.; FRANÇA NETO, J.B.; HENNING, A.A. Relato dos testes de vigor disponíveis para as grandes culturas. Informativo Abrates, v.1, n.2, p.15-59, 1991.

LABOURIAU, L.G. A germinação das sementes. Washington: OEA. 1983. $174 \mathrm{p}$.

LEDEUNF, Y. Hydration des semences de pois (Pisum sativum L.). Seed Science and Technology, v.17, n.3, p.471-483, 1989.

LEOPOLD, A.C. Temperature effects on soybean imbibition and leakage. Plant Physiology, v.65, n.2, p.1096-1098, 1980.

MARCOS FILHO, J. Germinação de sementes. In: CICERO, S.M.; MARCOS FILHO, J.; SILVA, W.R. (Org.) Atualização em produção de sementes. Campinas: Fundação Cargill, 1986. p.11-39.

MARCOS FILHO, J. Teste de envelhecimento acelerado. In: VIEIRA, R.D.; CARVALHO, N.M. (Coord.) Testes de vigor em sementes. Jaboticabal: FUNEP, 1994. p.133-149.

MARCOS FILHO, J.; CICERO, S.M.; SILVA, W.R. Avaliação da qualidade das sementes. Piracicaba: FEALQ, 1987. 230p. 
MAYER, A.M.; MAYBER, A.P. The germination of seeds. 2. ed. Oxford: Pergamon Press, 1978. $192 \mathrm{p}$.

McCORMAC , A.C.; KEEFE, P.D. Cauliflower (Brassica oleracea L.) seed vigour: imbibition effects. Journal of Experimental Botany, v.41, n.228, p.893-899, 1990.

McDONALD, M.B.; SULLIVAN, J.; LAUER, M.J. The pathway of water uptake in maize seeds. Seed Science and Technology, v.22, n.1, p.79-90, 1994.

McDONALD, M.B.; VERTUCCI, C.W.; ROOS, E.E. Seed coat regulation of soybean seed imbibition. Crop Science, v.28, n.6, p.987-992, 1988a.

McDONALD, M.B.; VERTUCCI, C.W.; ROOS, E.E. Soybean seed imbibition: water absortion by seeds parts. Crop Science, v.28, n.6, p.993-997, $1988 b$.

MOTTA, C.A.P.; SILVA, W.R. Efeitos de hidratação e desidratação no desempenho fisiológico de sementes de trigo. Pesquisa Agropecuária Brasileira, v.32, n.4, p.379-390, 1997.

MURPHY, J.B.; NOLAND, T.L. Temperature effects on seed imbibition and leakage mediated by viscosity and membranes. Plant Physiology, v.69, n.1/3, p.428-431, 1982.

OBROUCHEVA, N.V.; ANTIPOVA, O.V.; IVANOVA, I.M. Preparation and initiation of growth in axial organs in germinating quiescent seeds: 1 . Accumulation of osmotically active substances in axial organs of broad bean seeds. Russian Journal of Plant Physiology, v.40, n.5, p.742-748, 1993. 
POPINIGIS, F. Fisiologia da semente. Brasília: AGIPLAN, 1985. 289p.

POWELL, A.A.; MATTHEWS, S. The influence of testa condition on the imbibition and vigour of pea seeds. Journal of Experimental Botany, v.30, n.114, p.193-197, 1979.

ROCHA, V.S.; SEDIYAMA, T.; SILVA, R.F.; SEDIYAMA, C.S.; THIEBAUT, J.T.L. Embebição de água e qualidade fisiológica de sementes de soja. Revista Brasileira de Sementes, v.6, n.2, p.51-66, 1984.

ROSSETTO, C.A.V.; FERNANDEZ, E.M.; MARCOS FILHO, J. Metodologia de ajuste do grau de umidade e comportamento das sementes de soja no teste de germinação. Revista Brasileira de Sementes, v.17, n.2, p.171-178, 1995.

ROSSETTO, C.A.V.; NOVEMBRE, A.D.L.C.; MARCOS FILHO, J.; SILVA,W.R.; NAKAGAWA, J. Comportamento das sementes de soja durante a fase inicial do processo de germinação. Scientia Agricola, v.54, n.1/2, p.106115, 1997.

STATISTICAL ANALYSIS SISTEM INSTITUTE. SAS/STAT: Guide for personal computer version 6. Cary, 1987. 1028p.

SHEPHARD, H.L.; NAYLOR, R.E.L. Effect of the seed coat on water uptake and electrolyte leakage of sorghum (Sorghum bicolor (L.) Moench) seeds. Annals of Applied Biology, v.129, n.1, p.125-136, 1996.

SHIEH, W.J.; McDONALD, M.B. The influence of seed size, shape and treatment on inbred seed corn quality. Seed Science and Technology, v.10, n.2, p.307-313, 1982. 
SMITH, M.T; BERJAK, P. Deteriorative changes associated with the loss of viability of stored desiccation-tolerant and desiccation-sensitive seeds. In: KIGEL, J.; GALILI, G. (Ed.) Seed development and germination. New York: Marcel Dekker, 1995. cap.26, p.701-746.

SOUZA, F.H.D.; MARCOS FILHO, J. Physiological characteristics associated with water imbibition by Calopogonium mucunoides Desv. seeds. Seed Science and Technology, v.21, n.3, p.561-572, 1993.

SOUZA, F.H.D.; MARCOS FILHO, J.; NOGUEIRA, M.C.S. Características físicas das sementes de Calopogonium mucunoides Desv. associadas à qualidade fisiológica e ao padrão de absorção de água. I Tamanho. Revista Brasileira de Sementes, v.18, n.1, p.33-40, 1996.

VERTUCCI, C.W. The kinetics of seed imbibition: Controling factors and relevance to seedling vigor. In: STANWOOD, P.C.; McDONALD, M.B. (Ed.) Seed moisture. Madison: Crop Science Society of America, 1989. cap.6, p.93-115.

VERTUCCI, C.W.; LEOPOLD, C.A. Dynamics of imbibition by soybean embryos. Plant Physiology, v.72, n.1, p. 190-193, 1983.

VERTUCCI, C.W.; LEOPOLD, C.A. Water binding in legume seeds. Plant Physiology, v.85, n.1, p. 224-231, 1987.

VIEIRA, R.D. Teste de condutividade elétrica. In: VIEIRA, R.D.; CARVALHO, N.M. (Coord.) Testes de vigor em sementes. Jaboticabal: FUNEP, 1994. P. 133-149. 
WAGGONER, P. E.; PARLANGE, J.Y. Water uptake and water diffusivity of seeds. Plant Physiology, v.57, n.1/3, p.153-156, 1976.

WOODSTOCK, L.W. Seed imbibition: a critical period for successful germination. Journal of Seed Technology, v.12, n.1, p.1-15, 1988.

WOODSTOCK, L.W.; TAO, K.J. Prevention of imbibitional injury in low vigor soybean embrionic axes by osmotic control of water uptake. Physiologia Plantarum, v.51, n.1, p.133-139, 1981. 